\title{
Environmental Multifunctionality of Paddy Fields in Taiwan- A Conjunction Evaluation Method of Contingent Valuation Method and Analytic Network Procedures
}

\author{
Ya-wen Chiueh ${ }^{1}$ \\ ${ }^{1}$ Department of Environmental and Cultural Resources, National Hsinchu University of Education, Taiwan \\ Correspondence: Ya-wen Chiueh, Department of Environmental and Cultural Resources, National Hsinchu \\ University of Education, Taiwan. E-mail: yawen.chiueh@gmail.com
}

Received: July 25, 2012 Accepted: August 22, 2012 Online Published: November 8, 2012

doi:10.5539/enrr.v2n4p114

URL: http://dx.doi.org/10.5539/enrr.v2n4p114

\begin{abstract}
This study uses the benefit and value assessment method, in conjunction with a Contingent Valuation Method (CVM) and Analytic Network Procedures (ANP), through the use of questionnaires, to assess the preference structure and relative weight scales that are assigned to the multifunctionality function and production output benefits that are derived from paddy fields. The monetary benefits associated with the multifunctionality of paddy fields are as below: 1) Benefits from production are NT\$20.97 (NT\$1 about US\$0.03385) (US\$0.71), from $1 \mathrm{~kg}$ of rice, 2) Benefits to food safety and reliance are NT\$36.38 (US\$1.23), from $1 \mathrm{~kg}$ of rice, 3) Benefits to cultural heritage and community development are NT\$13.51 (US\$0.46), from $1 \mathrm{~kg}$ of rice, 4) Benefits to recreation and landscape are NT\$12.34 (US\$0.42), from $1 \mathrm{~kg}$ of rice, and 5) Benefits to environmental conservation are NT $\$ 25.4$ (US\$0.86), from $1 \mathrm{~kg}$ of rice. The ratio of nonmarket/rice production is 4.18 . The monetary benefits constitute the gross domestic product (GDP), for rice production. These benefits from all five categories constitute the green gross domestic product (Green GDP), for rice production. This study calculated the Green GDP, for rice production, which included the market price of rice production and the non-market value of the multifunctionality of paddy fields, which generated NT\$158 billion (US\$5.3483 billion), in 2008 . The ratio of rice production output to real production output, as defined by this study, obtained a result close to 1(0.97), showing that the benefit assessment for market goods and non-market goods, in conjunction with ANP and CVM, is a reliable assessment method, which should be promoted in the future.
\end{abstract}

Keywords: multifunctionality, contingent valuation method, analytic network process, conjunction evaluation method, green gross domestic product

\section{Introduction}

The multifunctionality of paddy field includes objective and subjective components. The objective components are based on factual aspects, such as the living conditions, ecological quality and economic development. The subjective components are based on both the use and nonuse value of the multifunctionality of a paddy field. However, prior to actual assessment, it is necessary to understand the values and preferences of people, with respect to the production of food, environmental effects, and the cultural impact of paddy fields. This study used the benefit and value assessment method, in conjunction with a Contingent Valuation Method (CVM) and Analytic Network Procedures (ANP), through the use of questionnaires, to assess the preference structure and relative weight scales assigned by individuals to the environmental and production output benefits that are derived from paddy fields.

The monetization of the value of the multifunctionality of paddy fields includes five categories of benefits, including 1) benefits from the value of the product, 2) benefits to food safety and reliance, 3) benefits to cultural heritage and community development, 4) benefits to recreation and landscape and 5) benefits to environmental conservation. The benefits from the value of the product constitute the GDP, for rice production. The benefits from all five categories constitute the Green GDP, for rice production. This study calculated the GGDP, for rice production, which includes the market price of rice production and the non-market value of the multifunctionality of paddy fields.

This study uses an evaluation method with ANP and CVM to calculate the Green GDP, for rice production, 
which includes the market price of the rice product and the non-market value of the multifunctionality of paddy fields, which constituted a figure of NT\$158 billion, in 2008. The ratio of rice production output to real production output ratio, as defined by this study, was close to 1, showing that the benefit assessment for market goods and non-market goods, in conjunction with ANP and CVM, is a reliable assessment method, which should be promoted in the future.

\section{Research Method}

According to a special task force of the International Water Association Asia Pacific Regional Group that worked on "the Multiple Roles and Diversity of Irrigation Water," the multifunctionality of paddy fields includes "food", "environment" and "culture" functions. The functions of food are a safe and stable food supply; the functions of environment include flood prevention, stable river flow, groundwater recharge, prevention of soil erosion and landslides, maintenance of biological diversity and landscape maintenance and the functions of culture include cultural values, traditions, practical experience and education in the field, as shown in Figure 1.

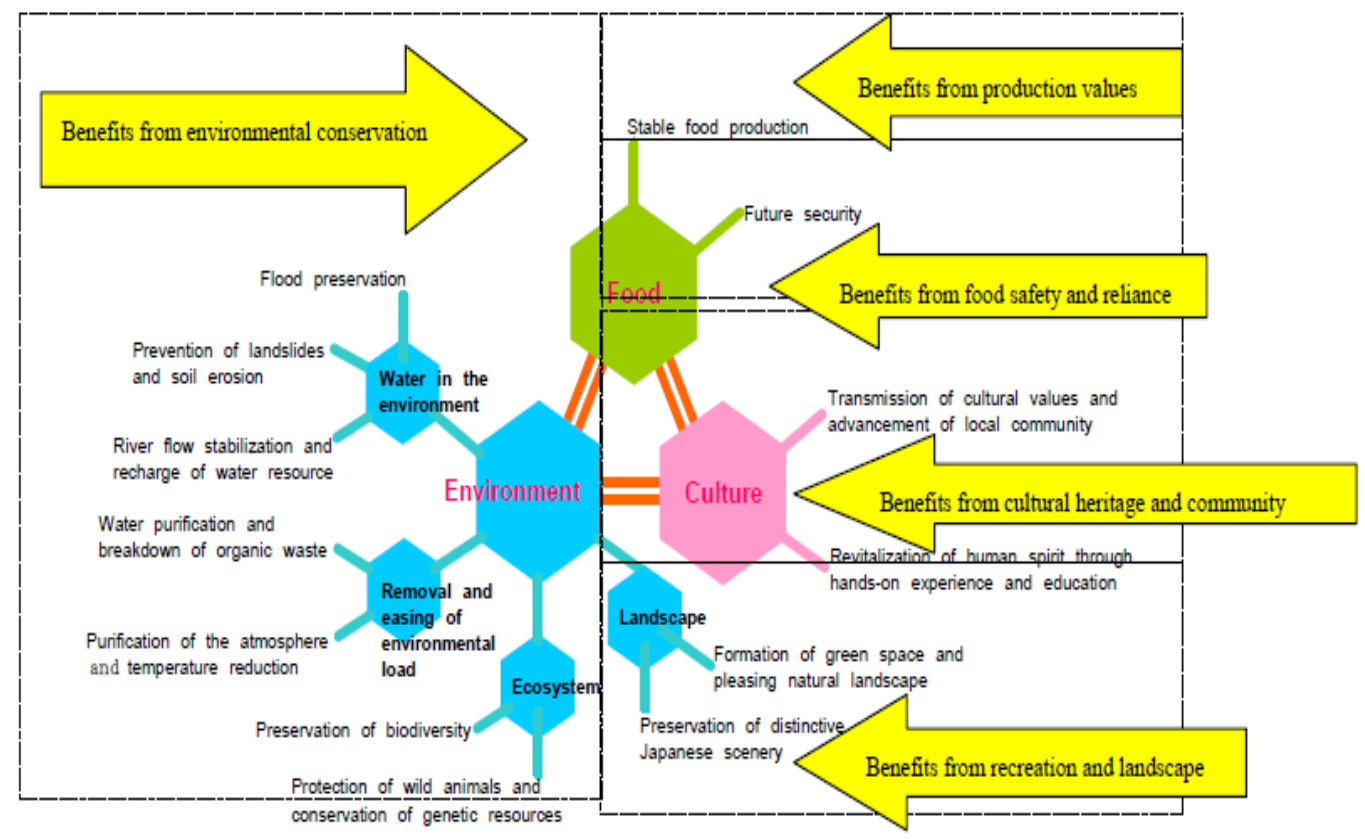

Figure 1. The benefits of multi-functionality of paddy

Source: This study revised from ASRWG (2006).

Jordan and Warner (2010) pointed out that agricultural production and environmental benefits were co-products. Agricultural production facilitates and, at the same time, derives environmental benefits of agriculture. Parlberg, et al. (2002) stated that the external benefits of multi-functionality of agriculture should be evaluated. Cocklin Mautner (2006) also indicated that agricultural land would affect the multi-functionality of the environment. The benefits of agricultural multifunctionality have been widely emphasized by countries all over the world. The Common Agricultural Policy (CAP) utilizes policy instruments to safeguard the multifunctionality of agriculture. Grant (2010) pointed out that policy instruments should be employed to safeguard the multi-functionality of agriculture under the reformed policy of the CAP. Kurkalova et al. (2006) discussed how to use green subsidies as increased incentives to motivate farmers to protect agricultural land and maintain the farming environment for the purpose of protecting the multifunctionality of agriculture. The research concluded that the distribution of subsidies had significant effect on the rising protection of agricultural land. Daniel and Kilkeenny (2009) believed that single farm payment would, nonetheless, better promote farmers' welfare and regional development. The evaluation of the benefits of agricultural multi-functionality enhances the promotion and implementation of related agricultural protection policies as well as the determination of the value of agricultural subsidies; it further helps making estimates on the green gross domestic product (GGDP). 
During the WTO technical meeting on Multilateral Environmental Agreements, the possible conflict between WTO rules and various international protocols and conventions on environmental protection was fiercely debated. Kim et al. (2006) indicated that the Asian monsoon regions should evaluate the characteristics of multi-functionality in paddy farming correctly and transmit them to the people of Western countries. This benefit assessment has objective and subjective components; the objective component is based on the veritable aspects of the benefits, which can be defined as the actual effects of "food", "environment", and "culture" functions, derived from rice production. The subjective component is based on more human aspects, for which we must first understand the value system and personal preferences of individuals, with respect to the benefits derived from the multifunctionality (i.e. the food, environment, and culture functions) of paddy fields, before any meaningful benefit assessment to be made.

The multifunctionality of rice production, based on the food, environment, and culture factors can actually enhance individuals' well-being. With respect to the human aspects, this article categorizes the multifunctional benefits of rice production into "benefits from the value of the product", representing the benefits of food production and income from paddy fields, as estimated from its market value, "benefits from food safety and reliance", representing the benefits to food safety and reliance that are established in the minds of individuals, over time, "benefits to cultural heritage and community development", representing the continuation of cultural values and community development and the benefits derived from actual experience and education in the field, in enhancing the human spirit, "benefits to recreation and landscape", including the benefits of green space and natural landscape and the benefits derived from the preservation of landscape, and "benefits from environmental conservation", including the benefits derived from flood water regulation, landslide prevention and prevention of soil loss, river flow stability, replenishment of groundwater, river flow controls, water purification and the decomposition of organic pollutants, air purification, regulation of temperature, maintenance of biological diversity, protection of wildlife, the preservation of genetics and other functions, indicated in Figure 1.

The benefits to food safety and reliance, the benefits to cultural heritage and community development, the benefits to recreation and landscape and the benefits to environmental conservation are considered as non-market good. The benefits from "the value of the product" are considered as market good and constitute the GDP, for rice production. Both the market and nonmarket good benefits of the multifunctionality of paddy fields constitute the Green GDP, for rice production.

In assessing the benefits derived from the food, environmental and cultural effects of rice production, most researches use the replacement method, or the Contingent Valuation Method (CVM) to assess the benefits derived from non-market goods, with respect to the multifunctionality of paddy fields. Aizaki et al. (2006) used a realistic assumption to measure the multifunctionality of agriculture and rural areas in Japan. Kallas et al. (2007) combining Contingent Valuation Method (CVM) and the Analytic Hierarchy Process (AHP) to decomposing the value of Agricultural multifunctionality. Chiueh and Chen (2008) used a Contingent Valuation Method (CVM) to assess the value of the environmental multifunctionality of paddy fields, from a purposely selected pool of samples in Taiwan. Chiueh (2002) had used Analytic Hierarchy Process (AHP) to assess the Green GDP from rice production.

Studies show that the CVM enables monetary assessment of the benefits of the multifunctionality of paddy fields. However, using the CVM for the overall assessment of the agricultural multifunctionality does not allow identification of each value of of multi-functions or paddy fields. The multifunctionality of rice production can be viewed as complex economic goods with complementary effects, since the food, environment and culture functions exist simultaneously and tend to complement each other. Generally speaking, it is not easy to distinguish the preference structure of consumers, because of the complexity of the agricultural multifunctionality in the complex economic goods. In this study's value assessment process, in order to evaluate the complexity of various properties and the preference structure derived from the agricultural multifunctionality, in conjunction with an Analytic Network Process (ANP), as these methods can provide good analytical results. This research attempts to develop a combined evaluation method, from the CVM and ANP, in order to provide an overall evaluation of the agricultural multifunctionality and to understand the preference structure of individuals, as derived from the agricultural multifunctionality, shown in Figure 2. 


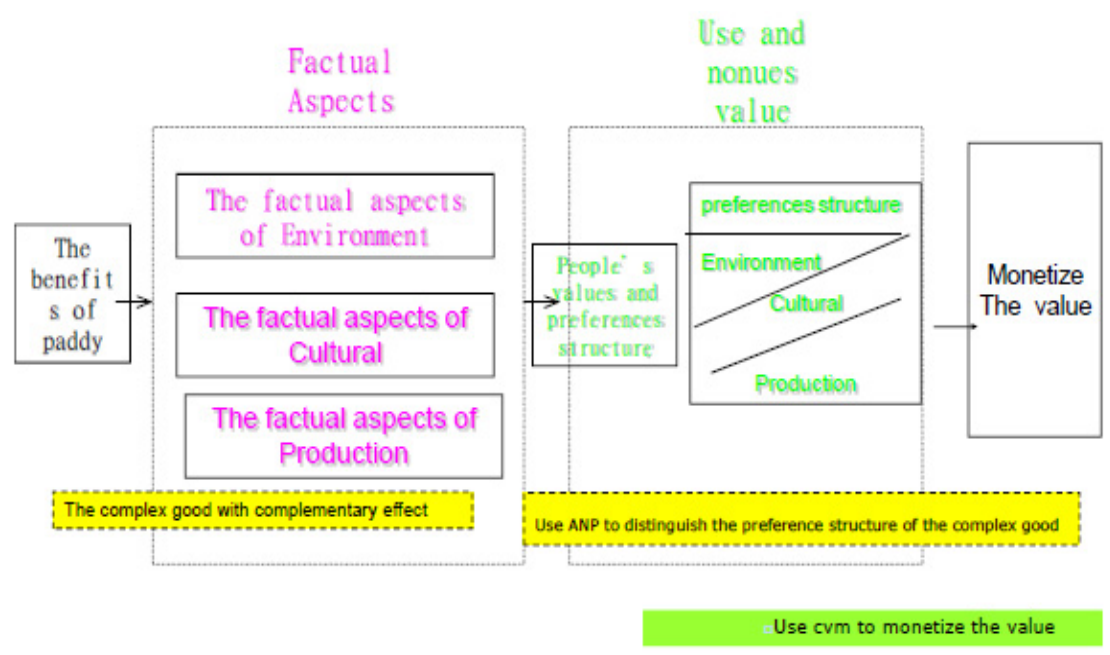

Figure 2. A conjunction evaluation method of contingent valuation method and analytic network procedures Source: This study.

\subsection{Analytic Network Process}

This study uses the benefit and value assessment method, in conjunction with Contingent Valuation Method (CVM) and Analytic Network Procedures (ANP), through the use of questionnaires, to assess the preference structure and relative weight scales assigned by individuals to the environmental and production output benefits that are derived from paddy fields. Chiueh (2002) had used Analytic Hierarchy Process (AHP) to assess the Green GDP from rice production, Kallas et al. (2007) combining Contingent Valuation Method (CVM) and the Analytic Hierarchy Process(AHP) to decomposing the value of Agricultural multifunctionality. The above study was constrained by the limitations of the AHP method, which assumed that the decision-making criteria were mutually independent and that there was no interaction of events. It is evident that their research is based on the assumption that the three functions of paddy fields are separate and independent. However, the validity of this assumption has been questioned by other researchers, as it does not conform to the human decision-making process (Saaty, 2008) and is also not supported by the fact that the three functions of paddy fields are dependent on each other and often occur simultaneously. Therefore, this research uses Analytical Network Procedures (ANP) to modify the valuation results. ANP is characterized by a process that is close to human thought processes. Since the decision-making criteria do not have to be independent, the dependency factor and feedback effects, such as the cluster interaction and feedback effect, can be included in the decision-making criteria. A supermatrix is then able to calculate the degrees of dependency, so that the original regularized hierarchical structure becomes a complex network structure, similar to an amoeba, enabling more appropriate descriptions of the characteristics of the problem by the researchers (Saaty, 2008).

Since the food, environment and culture functions of rice production are interdependent and mutually affect each other, Analytic Network Procedures (ANP) are eminently suitable to evaluation of the preference structure. This study develops the benefit and value assessment method, in conjunction with CVM and ANP, in order to assess the market and non-market benefits of economic goods and the preference structure, so as to provide an overall assessment of the benefits and preference structure of individuals, as derived from the multifunctionality of rice production.

Because it approximates human though processes and because the decision-making criteria need not be independent, ANP enables the original regularized hierarchical structure to be changed to a complex network structure, similar to an amoeba (Saaty, 2008). The food, environment and culture functions of rice production are interdependent and tend to influence each other in the process of producing the human benefits, shown in Figure 3.

This study uses a Supper Decisions software package, designed by Saaty, to calculate the ratio of the preference structure of the complex good, including "benefits from production values", "benefits from food safety and reliance", "benefits from cultural heritage and community development", "benefits from recreation and landscape" and "benefits from environmental conservation". 


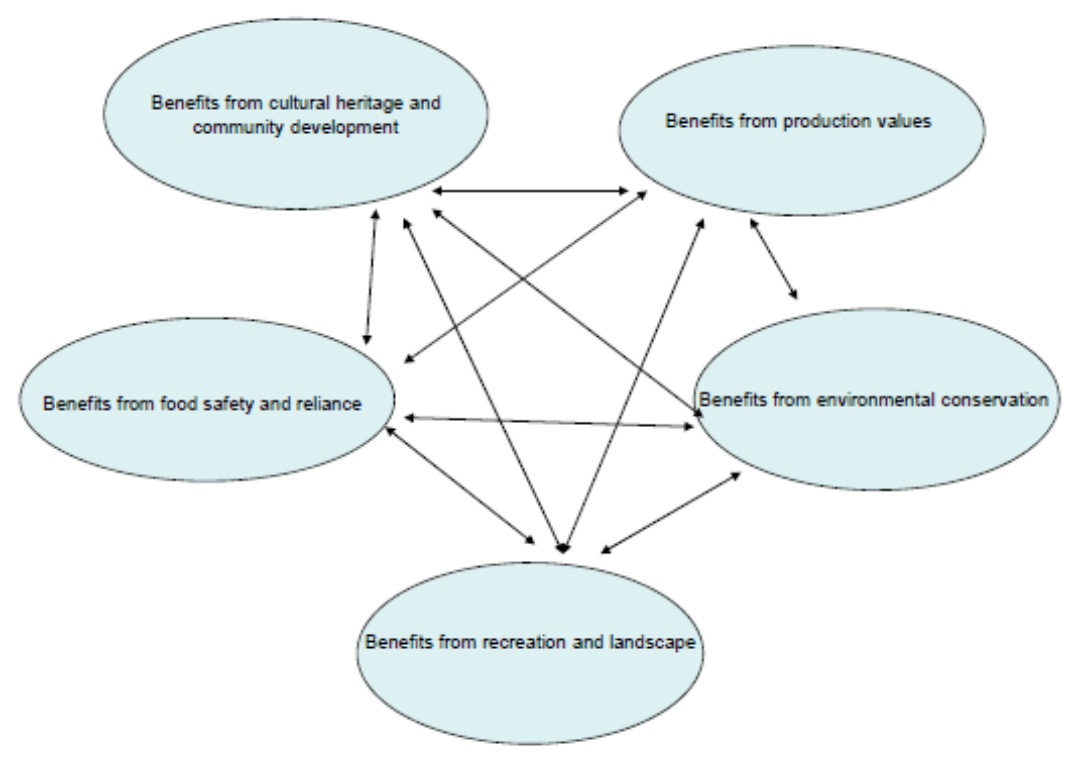

Figure 3. Complex network preference structure of multifunctionality of paddy fields

Source: This study.

Each ratio of preference of multifunctionality of paddy fields e shown below:

The ratio of preference that comes from the "benefits from production values" is $\mathrm{P} \%$;

The ratio of preference that comes from the "benefits from food safety and reliance" is F\%;

The ratio of preference that comes from the "benefits from cultural heritage and community development" is $\mathrm{C} \%$;

The ratio of preference that comes from the "benefits from recreation and landscape" is $\mathrm{R} \%$ and

The ratio of preference that comes from the "benefits from environmental conservation" is E\%.

\subsection{Contingent Valuation Method}

The household production model was employed when Freeman (1993) established his theory of benefit evaluation for non-market goods. Chiueh and Chen (2008) used this model to evaluate the environmental multifunctionality of paddy fields in Taiwan. The same model is used here. The differences between the paper of Chiueh and Chen (2008) and this paper are: 1) this paper evaluates the environmental, cultural and production multifunctionality of paddy fields in Taiwan and 2) this paper develops a conjunction evaluation method, from the CVM and ANP, in order to provide overall evaluation of the agricultural multifunctionality and to understand the preference structure of individuals, as derived from the agricultural multifunctionality.

Freeman (1993) and Chiueh and Chen (2008) stated that the price of general goods, $P_{X}$, the price of domestic rice products, $\mathrm{P}$, and the income, $\mathrm{M}$, for a given level of agriculture protection, $\mathrm{Q}$, are all independent variables that have an influence on the demand of the household. Freeman (1993) identified the indirect utility function $\mathrm{U}^{0}$ of the household, shown below.

$$
\mathrm{U}^{0}=\mathrm{V}\left(\mathrm{P}_{\mathrm{X}}, \mathrm{P}, \mathrm{Q}, \mathrm{M}\right)
$$

In light of the fact that this utility function is immeasurable, while expenditure functions can be easily measured, through the household behaviors, the correlation between the functions of indirect utility and expenditure convert Equation (1) into the expenditure function, below:

$$
\mathrm{E}=\mathrm{E}\left(\mathrm{P}_{\mathrm{X}}, \mathrm{P}, \mathrm{Q}, \mathrm{U}^{0}\right)
$$

Assuming a fixed utility level $\left(\mathrm{U}^{0}\right)$ and a constant price for X (PX), the interaction between $\mathrm{P}$ and $\mathrm{Q}$ can be defined by the expenditure function.

When the 5 categories of multifunctionality of paddy fields benefits improve and reaches a higher level of $\mathrm{Q}^{+}$, 
consumers' willingness-to-pay (WTP) equals the difference between the latter price and the original price, or the result of P1 minus P0. This is also called the compensating surplus (CS) for consumers. CS denotes consumers' WTP, in order to maintain the original bid level of E0, so that they enjoy a better multifunctionality of paddy fields benefits level, $\mathrm{Q}^{+}$, as the multifunctionality of paddy fields benefits changes, expressed in the expenditure function, below.

$$
\mathrm{E}\left(\mathrm{Q}^{0}, \mathrm{P}^{0}\right)=\mathrm{E}^{0}=\mathrm{E}\left(\mathrm{Q}^{+}, \mathrm{P}^{0}-\mathrm{CS}\right)=\mathrm{E}\left(\mathrm{Q}^{+}, \mathrm{P}^{0}-\mathrm{WTP}\right)
$$

This study's questionnaire aims to estimate the respondents' bid function, B (Q0,Q1,U0,W), in response to the restored multifunctionality of paddy fields benefits to agriculture, in the hypothetical market, as the economic benefit of paddy fields protection improves, as

$$
\mathrm{B}\left(\mathrm{Q}^{0}, \mathrm{Q}^{1}, \mathrm{U}^{0}, \mathrm{~W}\right)=\mathrm{E}\left(\mathrm{Q}^{0}, \mathrm{U}^{0}, \mathrm{~W}\right)-\mathrm{E}\left(\mathrm{Q}^{1}, \mathrm{U}^{0}, W\right)
$$

The bid function is shown below:

$$
\mathrm{W}=\mathrm{W}\left(\mathrm{P}, \mathrm{P}_{\mathrm{X}}, \mathrm{V}\right)
$$

In (5), the independent variable, $\mathrm{V}$, is the vector of the individual socio-economic characteristics. We defined the average WTP of the multifunctionality of paddy fields as W. In accordance with Cameron and James (1987), the bid function can be used to calculate the average WTP, of the multifunctionality of paddy fields. If the price suggested by the CVM questionnaire is T,

$$
\mathrm{W}(\mathrm{Q} 0, \mathrm{Q} 1, \mathrm{U} 0, \mathrm{~V}) \geq \mathrm{T}
$$

the probability for the interviewee to check this bid can be expressed by formula (7):

$$
\operatorname{Pr}=\operatorname{Pr}\left[\mathrm{W}^{*}(\mathrm{Q} 0, \mathrm{Q} 1, \mathrm{U} 0, \mathrm{~V})-\mathrm{T}>\mathrm{u}\right]
$$

Where $\mathrm{W}^{*}$ is observable component, $\mathrm{u}$ is observable random component, as shown in Formula (8):

$$
\mathrm{W}(\mathrm{Q} 0, \mathrm{Q} 1, \mathrm{U} 0, \mathrm{~S})=\mathrm{W}^{*}(\mathrm{Q} 0, \mathrm{Q} 1, \mathrm{U} 0, \mathrm{~S})+\mathrm{u}
$$

The Bidding Function can be estimated based on the probit model by Cameron and James (1987) as shown below:

$$
\begin{gathered}
\mathrm{Ii}=1 \text { if } \mathrm{Wi}>\mathrm{Ti} \\
=0 \text { otherwise } \\
\operatorname{Pr}(\mathrm{Ii}=1)=\operatorname{Pr}(\mathrm{Wi}>\mathrm{Ti})=\operatorname{Pr}\left(\mathrm{ui}>\mathrm{TI}-\mathrm{Xi}^{\prime} \mathrm{B}\right) \\
=\operatorname{Pr}\left(\mathrm{ui} / \sigma>\left(\mathrm{Ti}-\mathrm{Xi}{ }^{\prime} \mathrm{B}\right) / \sigma\right) \\
=1-\phi\left(\left(\mathrm{Ti}-\mathrm{Xi}{ }^{\prime} \mathrm{B}\right) / \sigma\right)
\end{gathered}
$$

where $\mathrm{Xi}^{\prime} \mathrm{B}$ is exclaiming variable, $\phi$ is accumulated probability of intensity function, then the interviewee's bidding valuation can be shown as formula (10) (Cameron \& James, 1987) :

$$
\mathrm{Wi}=\mathrm{Xi}^{\prime} \mathrm{B}+\mathrm{ui}
$$

Yet standard binary probit model shall be (Cameron \& James, 1987)

$$
\begin{gathered}
\mathrm{Ii}=1 \text { if } \mathrm{Wi}>0=0 \text { otherwise } \\
\operatorname{Pr}(\mathrm{Ii}=1)=\operatorname{Pr}(\mathrm{Wi}>0 \mathrm{i})=\operatorname{Pr}\left(\text { ui }>-\mathrm{wi}^{\prime} \delta\right) \\
=\operatorname{Pr}\left(\mathrm{zi}>-\mathrm{wi}^{\prime} \delta / \mathrm{v}\right) \\
=1-\phi\left(-\mathrm{wi}^{\prime} \delta / \mathrm{v}\right)
\end{gathered}
$$

at this time,

$$
\mathrm{Wi}=\mathrm{wi}^{\prime} \delta+\mathrm{ui}
$$

using the following transformation by Cameron and James (1987).

$$
\begin{gathered}
-\left(\mathrm{Ti}, \mathrm{Xi}^{\prime}\right)^{\left[\begin{array}{c}
-1 / \sigma \\
B / \sigma
\end{array}\right]}=-\mathrm{wi}^{\prime} \delta \\
\delta^{*}=(\alpha, \gamma)=(-1 / \sigma, \mathrm{B} / \sigma) \\
\text { we obtain } \\
\mathrm{B}=-\gamma / \alpha
\end{gathered}
$$




$$
\begin{array}{r}
\sigma=-1 / \alpha \\
W^{*}=\mathrm{Xi}^{\prime} \mathrm{B}
\end{array}
$$

Where $\mathrm{Wi}^{*}$ is the WTP of the multifunctionality of paddy fields.

This study uses the benefit and value assessment method, in conjunction with Contingent Valuation Method (CVM) and Analytic Network Procedures (ANP), to assess the preference structure and relative weight scales of individuals, in regard to the environmental and production output benefits that are derived from paddy fields.

The conjunction evaluation method, for the monetization of the multifunctionality of paddy fields is shown below:

The benefits from the value of the product are $\mathrm{w} * \mathrm{P} \%$;

The benefit to food safety and reliance is $\mathrm{w} * \mathrm{~F} \%$;

The benefit to cultural heritage and community development is $\mathrm{w} * \mathrm{C} \%$;

The benefit to recreation and landscape is $\mathrm{w} * \mathrm{R} \%$ and

The benefit to environmental conservation is $\mathrm{w} * \mathrm{E} \%$.

\section{Questionnaire Design and Survey Sampling}

The purpose of this study is to assess the preference structure and the relative balance scale of individuals, as derived from the food, environmental and cultural benefits of rice production. Another purpose is to enable the monetization of the overall production value from paddy fields, including market goods and non-market goods, in order to calculate the green GDP, from rice production. The Contingent Valuation Method (CVM) and the Analytic Network Process method (ANP) both rely on questionnaires, to assess the spiritual values, economic values and the preference structure of respondents.

Respondents must have prior knowledge of the event to be evaluated; this study used a deliberate sampling method to select the samples. Experts who participated in the survey were selected for their abilities in operational implementation or involvement in research in the field of multifunctionality of paddy fields. The value assessment, in conjunction with CVM and ANP, is associated with the willingness to pay, i.e. the dollar amounts that the expert group, whose members are currently not engaged in the rice-growing business, suppose will be paid. The group of experts is defined as a group of experts not involved in the rice production businesses. However, those involved in the operational implementation or in research associated with paddy fields, working for the Water Resources Agency, or the middle-to-top level management of the Council of Agriculture, or scholars from the water conservancy, or from the agricultural economics field, are defined as "experts not involved in the operation of agricultural business", shows in Table 1. The sampling of conjunction Analytic with CVM and ANP is from the group.

Mail surveys were used, but the initial response rate of the mail survey was very low. However, following persuasive telephone follow-ups, the selected experts, who were all involved in research concerning this issue, the ratio of mail replies to the total number of questionnaires was $58.24 \%$. Discounting the invalid returns, the ratio of effective questionnaires was still more than $40 \%$. Sampling design, questionnaire schedule and the response rate to the survey are shown in Table 2 .

With respect to the questionnaire design, the first page elicits basic information about the multifunctional aspects of rice production. The first question examines the knowledge and level of concern of respondents, with regard to the multifunctional aspects of rice production. 
Table 1. Questionnaire design

\begin{tabular}{lcc}
\hline Experts not involved in the operation of agricultural business & Questionnaire Return questionnaires \\
\hline Agriculture and Food Agency & 30 & 24 \\
Water Resources Agency & 20 & 9 \\
Soil and Water Conservation Bureau & 10 & 7 \\
Forestry Bureau & 10 & 9 \\
Taiwan Forestry Research Institute & 10 & 5 \\
Agricultural Research and Extension Station & 30 & 19 \\
Endemic Species Research Institute & 10 & 2 \\
Taiwan Agricultural Research Institute & 20 & 11 \\
Tsao-Jiin Memorial Foundation for R\&D for Agricultural and Irrigation & 6 & 3 \\
Argicultural Engineering Research Center & 6 & 1 \\
Taiwan International Institute for water Education & 6 & 5 \\
Chi-Hsin Agricultural Development Foundation & 6 & 5 \\
Taichung Environment Greening Foundation & 6 & 5 \\
National Taiwan University & 30 & 24 \\
Leader University & 5 & 1 \\
National Chiao Tung University & 5 & 1 \\
National Cheng Kung University & 5 & 1 \\
National Ilan University & 5 & 2 \\
Minghsin University of science and technology & 5 & 1 \\
National Pingtung University of Science and technology & 6 & 5 \\
Taoyuan Irrigation Association & 5 & 1 \\
National Taiwan Ocean University & 5 & 3 \\
Tamkang University & 6 & 4 \\
Tsao-Jiin Memorial Foundation for R\&D for Agricultural and Irrigation & 5 & 1 \\
Vanung University & 5 & 2 \\
I-Shou University & 6 & 5 \\
Overseas Chinese University & 5 & 2 \\
Agricultural Engineering Research Center & 5 & 159 \\
Total & 273 &
\end{tabular}

Table 2. Survey Sampling and response rate

\begin{tabular}{ll}
\hline Respondents & experts not involved in the operation of agricultural business \\
\hline Questionnaire design & ANP + CVM \\
Survey Period & $8 / 10 / 09-9 / 10 / 09$ \\
Questionnaire & 273 \\
Return questionnaires & 159 \\
Return Rate (\%) & 58.24 \\
Valid Samples & 115 \\
Response rate (\%) & 42.12 \\
\hline
\end{tabular}

Source: Questionnaire survey of this study.

The second question uses $2 \times 2$ pair-wise comparisons, to determine the respondents' preference structure with regard to the multifunctionality of paddy fields. The pair-wise comparison questions are: I would like to ask you, which multifunctionality of paddy fields you prefer better than the other and how much you prefer it in comparison with the other. The pair-wise comparison table shows in Table 3. 
Table 3. Pair-wise comparison table

\begin{tabular}{|c|c|c|c|c|c|c|c|c|c|c|}
\hline $\begin{array}{l}\text { Multifunctionality } \\
\text { of paddy }\end{array}$ & $\begin{array}{l}\text { Extreme } \\
\text { preference }\end{array}$ & $\begin{array}{l}\text { Very } \\
\text { Strong } \\
\text { preference }\end{array}$ & $\begin{array}{l}\text { Strongly } \\
\text { preference }\end{array}$ & $\begin{array}{l}\text { Slightly } \\
\text { preference }\end{array}$ & Equal & $\begin{array}{l}\text { Slightly } \\
\text { preference }\end{array}$ & $\begin{array}{l}\text { Strongly } \\
\text { preference }\end{array}$ & $\begin{array}{l}\text { VeryStringp } \\
\text { reference }\end{array}$ & $\begin{array}{l}\text { Extreme } \\
\text { preference }\end{array}$ & $\begin{array}{l}\text { Multifunctiona } \\
\text { lity of paddy }\end{array}$ \\
\hline $\begin{array}{lr}\text { Benefits } & \text { from } \\
\text { cultural heritage } \\
\text { and community } \\
\text { development }\end{array}$ & 9 & 7 & 5 & 3 & 1 & 3 & 5 & 7 & 9 & $\begin{array}{l}\text { Benefits from } \\
\text { food safety } \\
\text { and reliance }\end{array}$ \\
\hline $\begin{array}{lr}\text { Benefits } & \text { from } \\
\text { cultural heritage } \\
\text { and community } \\
\text { development }\end{array}$ & 9 & 7 & 5 & 3 & 1 & 3 & 5 & 7 & 9 & $\begin{array}{l}\text { Benefits from } \\
\text { recreation and } \\
\text { landscape }\end{array}$ \\
\hline $\begin{array}{lr}\text { Benefits } & \text { from } \\
\text { cultural } & \text { heritage } \\
\text { and } & \text { community } \\
\text { development }\end{array}$ & 9 & 7 & 5 & 3 & 1 & 3 & 5 & 7 & 9 & $\begin{array}{l}\text { Benefits from } \\
\text { environmental } \\
\text { conservation }\end{array}$ \\
\hline $\begin{array}{lr}\text { Benefits } & \text { from } \\
\text { cultural heritage } \\
\text { and community } \\
\text { development }\end{array}$ & 9 & 7 & 5 & 3 & 1 & 3 & 5 & 7 & 9 & $\begin{array}{l}\text { Benefits from } \\
\text { production } \\
\text { values }\end{array}$ \\
\hline $\begin{array}{l}\text { Benefits from food } \\
\text { safety and reliance }\end{array}$ & 9 & 7 & 5 & 3 & 1 & 3 & 5 & 7 & 9 & $\begin{array}{l}\text { Benefits from } \\
\text { recreation and } \\
\text { landscape }\end{array}$ \\
\hline $\begin{array}{l}\text { Benefits from food } \\
\text { safety and reliance }\end{array}$ & 9 & 7 & 5 & 3 & 1 & 3 & 5 & 7 & 9 & $\begin{array}{l}\text { Benefits from } \\
\text { environmental } \\
\text { conservation }\end{array}$ \\
\hline $\begin{array}{l}\text { Benefits from food } \\
\text { safety and reliance }\end{array}$ & 9 & 7 & 5 & 3 & 1 & 3 & 5 & 7 & 9 & $\begin{array}{l}\text { Benefits from } \\
\text { production } \\
\text { values }\end{array}$ \\
\hline $\begin{array}{lr}\text { Benefits } & \text { from } \\
\text { recreation } & \text { and } \\
\text { landscape } & \end{array}$ & 9 & 7 & 5 & 3 & 1 & 3 & 5 & 7 & 9 & $\begin{array}{l}\text { Benefits from } \\
\text { environmental } \\
\text { conservation }\end{array}$ \\
\hline $\begin{array}{lr}\text { Benefits } & \text { from } \\
\text { recreation } & \text { and } \\
\text { landscape } & \end{array}$ & 9 & 7 & 5 & 3 & 1 & 3 & 5 & 7 & 9 & $\begin{array}{l}\text { Benefits from } \\
\text { production } \\
\text { values }\end{array}$ \\
\hline $\begin{array}{l}\text { Benefits from } \\
\text { environmental } \\
\text { conservation }\end{array}$ & 9 & 7 & 5 & 3 & 1 & 3 & 5 & 7 & 9 & $\begin{array}{l}\text { Benefits from } \\
\text { production } \\
\text { values }\end{array}$ \\
\hline
\end{tabular}

Source: This study.

The third question is related to the Contingent Valuation Method. Supposing the agricultural free trade agreement affects the food, environment and culture functions of paddy fields, to cause the original benefits to be reduced by $5 \%$, but also supposing a willingness to pay a little more money to buy Taiwan-grown rice, on the part of the Taiwanese people, in order to enable Taiwan to restore the multifunctionality of rice production back to its original "food", "environment" and "culture" functions, respondents are asked: If the price of same quality Taiwan rice for each Taiwanese kilo is higher than imported rice by 1 (or 2,3,4,5,6,7,8,9,10,12,14,17,20,25, we only give on bid money in one Questionnaire) NTD, are you still willing to buy Taiwan-grown rice, so as to allow the multifunctionality of paddy fields to be improved by $5 \%$, to regain the present level? For the dollar amount, the respondent chooses one of 15 different amounts. Next, we have a question to detect the protest sample, including "No, I would not purchase the rice", and "No, I do not want to pay, because I do not think the added money will feedback to farmer".

The last part of the questionnaire asks the respondents about socio-economic variables, to facilitate data Analysis.

\section{Empirical Results}

\subsection{Contingent Valuation Method}

Using the postulate of a linear bid function and with the help of the LIMDEP software package, the multifunctional benefits of paddy fields, as perceived by the respondents, for certain specified scenarios, is easily 
determined. The "15 different bids" and the ratios of "yes" in each bid show in Table 4 . The results of the multifunctional benefits of paddy fields, given by experts not involved in the operation of agricultural business, are summarized in Table 5. Among various individual variables, all t-ratios are significant. The predictions of the empirical models are $90.435 \%$ correct. On the whole, the Chi-square test confirms that the models achieve a level of significance.

The factors in the bid function that have a higher significance level include WTP (The cutoff points of the WTP), VA (in regard to benefits from Production values), VB (in regard to benefits to Food safety and reliance values), VC (in regard to benefits to cultural heritage and community development values), EDU (The respondent's level of education) and EXP (Regular monthly expenditure of the responding household). This demonstrates that the cognition variables of the respondents are the significant variables noted by most previous literature, in relation to CVM evaluation. Moreover, the respondent's expenditure level also plays an important role in the price bid, which is also consistent with the assumptions of the model.

For the scenario of a $5 \%$ decrease in the respective arable paddy land, to be restored later, the respondents' willingness to pay for the multifunctionality of paddy fields (w) was NT $\$ 108.64$ per $1 \mathrm{~kg}$ of rice (NT\$ $/ \mathrm{Kg} /$ rice).

Table 4. The "15 different bids" and the ratios of "yes" in each bid

\begin{tabular}{cc}
\hline 15 different bids(NT) & the ratios of "yes" \\
\hline 1 & $81.82 \%$ \\
2 & $93.33 \%$ \\
3 & $80.00 \%$ \\
4 & $93.75 \%$ \\
5 & $88.89 \%$ \\
6 & $100.00 \%$ \\
7 & $100.00 \%$ \\
8 & $81.82 \%$ \\
9 & $90.91 \%$ \\
10 & $100.00 \%$ \\
12 & $70.00 \%$ \\
14 & $50.00 \%$ \\
17 & $83.33 \%$ \\
20 & $100.00 \%$ \\
25 & $88.89 \%$ \\
\hline
\end{tabular}

Source: Questionnaire survey of this study.

Table 5. Empirical results of CVM

\begin{tabular}{|c|c|c|c|c|c|}
\hline PROBIT Model & Coeff. & \multicolumn{2}{|c|}{ Std.Err. } & t-ratio & $P$-value \\
\hline ONE(a constant term) & -6.1483 & \multicolumn{2}{|c|}{2.4293} & -2.5309 & 0.0114 \\
\hline WTP (The cutoff points of the WTP) & -0.0293 & \multicolumn{2}{|c|}{0.0251} & $-1.1665^{*}$ & 0.2434 \\
\hline VA(pay attention to benefits from Production values) & 2.8309 & \multicolumn{2}{|c|}{1.8512} & $1.5293 * *$ & 0.1262 \\
\hline $\begin{array}{l}\text { VB (pay attention to benefits from Food safety and } \\
\text { reliance values) }\end{array}$ & 3.8043 & \multicolumn{2}{|c|}{1.6129} & $2.3587 * * *$ & 0.0183 \\
\hline $\begin{array}{l}\text { VC (pay attention to benefits from cultural heritage } \\
\text { and community development values) }\end{array}$ & 7.9254 & \multicolumn{2}{|c|}{3.9100} & $2.0270 * * *$ & 0.0427 \\
\hline EDU (The respondent's education attainment) & 0.6130 & \multicolumn{2}{|c|}{0.2821} & $2.1728 * * *$ & 0.0298 \\
\hline $\begin{array}{l}\text { EXP (Regular monthly expenditure of the } \\
\text { responding household) }\end{array}$ & 0.2441 & \multicolumn{2}{|c|}{0.1039} & $2.3497 * * *$ & 0.0188 \\
\hline Number of observations & & \multicolumn{3}{|c|}{115} & \\
\hline Restricted log likelihood & & \multicolumn{3}{|c|}{$\begin{array}{l}-38.4712 \\
90.435 \%\end{array}$} & \\
\hline Correct prediction & & \multicolumn{3}{|c|}{$90.435 \%$} & \\
\hline \multicolumn{3}{|c|}{$\begin{array}{l}\text { Average willingness to pay (WTP) for the multifunctionality of } \\
\text { paddy fields. }(\$ / \mathrm{Kg} / \text { rice })\end{array}$} & \multicolumn{2}{|c|}{$\begin{array}{l}108.64 \mathrm{NT} \$ / \mathrm{Kg} / \mathrm{ric} \\
\mathrm{US} \$ / \mathrm{Kg} / \text { rice) }\end{array}$} & ice \\
\hline
\end{tabular}




\subsection{Analytic Network Procedures}

This research uses Analytic Network Procedures (ANP) to modify the valuation results. The Supper Decisions software package is used to calculate the ratio of the preference structure of "benefits from production value", "benefits to food safety and reliance", "benefits to cultural heritage and community development" "benefits to recreation and landscape" and "benefits to environmental conservation". The empirical results are shown in Table 6. On aggregate, the results of the survey show that the relative weight scales of individuals' preferences are: 1) benefits from production values are $19.30 \%$; 2) benefits to food safety and reliance are $33.49 \%$; 3 ) benefits to cultural heritage and community development are $12.44 \%$; 4) benefits to recreation and landscape are $11.36 \%$ and 5 ) benefits from environmental conservation are $23.42 \%$.

The experts thought that the benefits to food safety and reliance are the most important benefits of paddy fields in Taiwan. A partial explanation for this may lie with the changing climate and the special political position of Taiwan.

In conclusion, the preference structure of the relative weight scales of the market good (the benefits from the value of the product) are $19.30 \%$, while those of the non-market good, including "benefits to food safety and reliance"; "benefits to cultural heritage and community development"; "benefits to recreation and landscape" and "benefits to environmental conservation", are $80.70 \%$.

Table 6. The preferences structure of experts not involved in the operation of agricultural business

\begin{tabular}{|c|c|c|c|c|c|}
\hline Preference Ratio & Mean & Std.Dev. & Minimum & Maximum & NumCases \\
\hline Production values $(\mathrm{P})$ & 0.1930 & 0.1242 & 0.0250 & 0.6450 & 115 \\
\hline Food safety and reliance values $(\mathrm{F})$ & 0.3349 & 0.1445 & 0.0330 & 0.6920 & 115 \\
\hline $\begin{array}{l}\text { cultural heritage and community } \\
\text { development values(C) }\end{array}$ & 0.1244 & 0.0637 & 0.0300 & 0.3110 & 115 \\
\hline $\begin{array}{c}\text { Recreation and landscape } \\
\text { values }(\mathrm{R})\end{array}$ & 0.1136 & 0.0673 & 0.0190 & 0.3140 & 115 \\
\hline $\begin{array}{c}\text { Environmental conservation } \\
\text { values(E) }\end{array}$ & 0.2342 & 0.1201 & 0.0340 & 0.5250 & 115 \\
\hline Total & 1 & - & - & - & - \\
\hline
\end{tabular}

Source: Questionnaire survey of this study.

\subsubsection{The Combination of the Contingent Valuation Method and Analytic Network Procedures}

This study uses the benefit and value assessment method, in conjunction with Contingent Valuation Method (CVM) and Analytic Network Procedures (ANP), through the use of questionnaires, to assess the preference structure and relative weight scales of individuals, with regard to the environmental and production benefits that are derived from paddy fields. The monetary value associate with each function of paddy fields are as below:

1) Benefits from production are NT $\$ 20.97$ (US\$0.71), from $1 \mathrm{~kg}$ of rice,

2) Benefits to food safety and reliance are NT\$36.38 (US\$1.23), from $1 \mathrm{~kg}$ of rice,

3) Benefits to cultural heritage and community development are NT\$13.51 (US\$0.46), from $1 \mathrm{~kg}$ of rice,

4) Benefits to recreation and landscape are NT\$12.34(US\$0.42), from $1 \mathrm{~kg}$ of rice, and

5) Benefits to environmental conservation are NT\$25.4(US\$0.86), from $1 \mathrm{~kg}$ of rice.

These values are shown in Table 7. The ratio of nonmarket/rice production is 4.18, as shown in Table 8.

The benefits from the value of the product constitute the GDP, for rice production. The benefits from all five categories constitute the Green GDP, for rice production. This study calculated the GGDP of rice production, including the market price of rice production and the non-market value of the multifunctionality of paddy fields as NT $\$ 158$ billion (US\$5.3483 billion), in 2008. The ratio of rice production output to real production output ratio, as defined by this study, was close to $1(0.9742)$, shown in Table 9 . This result shows that the benefit assessment for market goods and non-market goods, in conjunction with ANP and CVM, is a reliable assessment method and should be promoted, in the future. 
Table 7. Empirical Results of conjunction evaluation method

\begin{tabular}{|c|c|}
\hline Benefits (NT/Kg) & $\begin{array}{l}\text { experts not involved in the operation of } \\
\text { agricultural business }\end{array}$ \\
\hline $\begin{array}{l}\text { Production values } \\
(=\mathbf{W} * \mathbf{P} \%)\end{array}$ & NT\$20.97 (US\$0.71) \\
\hline Food safety and reliance values & NT\$36.38 (US\$1.23) \\
\hline $\begin{array}{l}\text { cultural heritage and community development values } \\
(=\mathbf{w} * \mathbf{C} \%)\end{array}$ & NT\$13.51 (US\$0.46) \\
\hline $\begin{array}{l}\text { Recreation and landscape values } \\
(=\mathbf{w} * \mathbf{R} \%)\end{array}$ & NT\$12.34(US\$0.42) \\
\hline $\begin{array}{l}\text { Environmental conservation values } \\
(=\mathbf{w} * \mathbf{E} \%)\end{array}$ & NT\$25.4(US\$0.86) \\
\hline Total $(\$ / K g)$ & NT\$108.64 (US\$3.6774) \\
\hline
\end{tabular}

Source: Questionnaire survey of this study.

Table 8. The ratios of nonmarket/rice production

\begin{tabular}{lc}
\multicolumn{1}{c}{ ratios } & $\begin{array}{c}\text { experts not involved in the operation } \\
\text { of agricultural business }\end{array}$ \\
\hline $\begin{array}{l}\text { Production values } \\
(=\mathrm{P} / \mathrm{P})\end{array}$ & 1 \\
The ratios of Food safety and reliance values / Production \\
values \\
$(=\mathrm{F} / \mathrm{P})$ \\
$\begin{array}{l}\text { The ratios of cultural heritage and community development } \\
\text { values / Production values } \\
(=\mathrm{C} / \mathrm{P})\end{array}$ \\
$\begin{array}{l}\text { The ratios of Recreation and landscape values / Production } \\
\text { values } \\
(=\mathrm{R} / \mathrm{P})\end{array}$ \\
$\begin{array}{l}\text { The ratios of Environmental conservation values / } \\
\text { Production values } \\
(=\mathrm{E} / \mathrm{P})\end{array}$ \\
$\begin{array}{l}\text { The ratios of GGDP of Paddy field production / Production } \\
\text { values } \\
(=(\mathrm{P}+\mathrm{F}+\mathrm{C}+\mathrm{R}+\mathrm{E}) / \mathrm{P})\end{array}$ \\
$\begin{array}{l}\text { The ratios of nonmarket value of multi-functionality of } \\
\text { paddy field / Production values } \\
(=(\mathrm{F}+\mathrm{C}+\mathrm{R}+\mathrm{E}) / \mathrm{P})\end{array}$
\end{tabular}

Source: Questionnaire survey of this study. 
Table 9. The ratio of rice production output to real production output ratio

\begin{tabular}{|c|c|c|c|}
\hline GGDP of Paddy production & $\begin{array}{l}\text { Use } 2008 \text { gap of Paddy } \\
\text { production } \\
\text { to calculate GGDP } \\
\text { (. a thousandN.T.D.) }\end{array}$ & $\begin{array}{l}\text { use WTP to } \\
\text { calculate(108.64N.t/Kg) } \\
\text { GGDP } \\
\text { (.a thousandN.T.D.) }\end{array}$ & $\begin{array}{l}\text { WTP/Real } \\
\text { GDP }\end{array}$ \\
\hline Production values & $31,362,747$ & $30,552,689$ & 0.9742 \\
\hline $\begin{array}{l}\text { Food safety and reliance } \\
\text { values }\end{array}$ & $44,197,348$ & $53,016,040$ & - \\
\hline $\begin{array}{lr}\text { cultural } & \text { heritage and } \\
\text { community } & \text { development } \\
\text { values } & \end{array}$ & $17,342,565$ & $19,693,029$ & - \\
\hline $\begin{array}{l}\text { Recreation and landscape } \\
\text { values }\end{array}$ & $15,977,768$ & $17,983,344$ & - \\
\hline $\begin{array}{l}\text { Environmental conservation } \\
\text { values }\end{array}$ & $31,376,532$ & $37,074,818$ & - \\
\hline $\begin{array}{l}\text { GGDP of Paddy field } \\
\text { production }\end{array}$ & $140,256,961$ & $158,319,922$ & - \\
\hline
\end{tabular}

Source: Questionnaire survey of this study.

\section{Conclusion and Recommendation}

This study used the benefit and value assessment method, in conjunction with the Contingent Valuation Method (CVM) and Analytic Network Procedures (ANP), through the use of questionnaires, to assess the preference structure and relative weight scales of individuals, with respect to the environmental and production output benefits that are derived from paddy fields. The monetization of the cost of total production output from paddy fields included two important production factors, market goods and non-market goods. This study calculated the GGDP of rice production, which included the market price of rice production and non-market value of multifunctionality of paddy fields, as NT $\$ 158$ billion, in 2008 . The ratio of rice production output to real production output ratio, as defined by this study, was close to 1 (0.9742), showing that the benefit assessment for market goods and non-market goods, in conjunction with ANP and CVM, is a reliable assessment method that should be promoted, in the future. By the way, the respondents are not general public, but experts; This would be a limitation of this research.

\section{Acknowledge}

The article was extracted from detailed project "Set up the indicators in utilization efficiency of agricultural water resource" that sponsored by the Council of Agriculture, Executive Yuan, Taiwan (project code: 98coa-7.4.1-water-b1(20)). The authors would like to thank the anonymous reviewers and all the participants of this project for their efforts.

\section{Reference}

Aizaki Hideo, Kazuo Sato, \& Hiroshi Osari. (2006) Contingent Valuation Approach in Measuring the Multifunctionality of Agriculture and Rural Areas in Japan. Paddy and Water Environment, 4, 217-222. http://dx.doi.org/10.1007/s10333-006-0052-8

Asian Regional Working Group (ASRWG). (2006). International Commission on Irrigation and Drainage, Multiple Roles and Diversity of Irrigation Water-Water and Eco-agriculture for Bio and Cultural Diversity.

Cameron, T. A., \& James, M. D. (1987). Estimating Willingness to Pay from Survey Data: An Alternative Pre-Test-Market Evaluation Procedure. Journal of Marketing Research, 24(3), 89-95. http://dx.doi.org/10.2307/3151386

Chang Koyin, \& Yung-hsiang Ying. (2005). External Benefits of Preserving Agricultural Land: Taiwan's Rice Fields. The Social Science Journal, 42, 285-293. http://dx.doi.org/10.1016/j.soscij.2005.03.008

Chapagain, A. K., \& Hoekstra, A. Y. (2004). Water Footprints of Nations. Institute for Water Education.

Chiueh, Ya-wen, \& Ming-chien Chen. (2008). Multifunctionality of paddy fields in Taiwan- an Application of 
Contingent Valuation Method. Paddy and Water Environment, 6, 229-236. http://dx.doi.org/10.1007/s10333-008-0110-5

Chiueh, Ya-wen. (2002). The GGDP of Agricultural Sector in Taiwan. Taiwan Research Institution.

Cocklin, C., Dibden, J., \& Mautner, N. (2006). From market to multifunctionality? Land stewardship in Australia. The Geographical Journal, 172(3), 197-205. http://dx.doi.org/10.1111/j.1475-4959.2006.00206.x

Daniel, K., \& Kilkenny, M. (2009). Agricultural Subsidies and Rural Development. Jounal of Agricultural Economics, 60(3), 504-529. http://dx.doi.org/10.1111/j.1477-9552.2009.00214.x

Freeman, A. M. (1993). The Measurment of Environmental and Resource Values Theory and Methods. Washington, D. C.: Resources for the Future.

Grant, Wyn. (2010). Policy Instruments in the Common Agricultural Policy. West European Politics, 33(1), 22-38. http://dx.doi.org/10.1080/01402380903354049

Jordan, N., \& Warner, N. D. (2010). Enhancing the Multifunctionality of US Agriculture. BioScience, 60(1). http://dx.doi.org/10.1525/bio.2010.60.1.10

Kallas, Z., Jose, A., Gomez-Limon \& Jesus Barreiro Hurle. (2007). Decomposing the Value of Agricultural Multifunctionality: Combining contingent Valuation and the Analytical Hierarchy Process. Journal of Agricultural Economics. http://dx.doi.org/10.1111/j.1477-9552.2007.00085.x

Kim Tai-Cheol, Uhn-Soon Gim, Jin Soo Kim, \& Dae-Sik Kim (2006) The Multi-Functionality of Paddy Farming in Korea. Paddy and Water Environment, 4, 169-179. http://dx.doi.org/10.1007/s10333-006-0046-6

Kurkalova, L., Kling, C., \& Zhao, J. (2006). Green Subsidies in Agriculture: Estimating the Adoption Costs of Conservation Tillage from Observed Behavior. Canadian Journal of Agricultural Economics, 54, $247-267$. http://dx.doi.org/10.1111/j.1744-7976.2006.00048.x

Parlberg, P. L., Bredahl, M., \& Lee, J. G. (2002). Multifunctionality and Agricultural Trade Negotiations. Review of Agricultural Economics , 24(2), 322-335. http://dx.doi.org/10.1111/1467-9353.00022

Saaty, Thomas, L. (2008). The Encyclicon, Volume 2: A Dictionary of Complex Decisions using the Analytic Network Process, with Brady Cillo. 